\title{
Correction: Quorum sensing provides a molecular mechanism for evolution to tune and maintain investment in cooperation
}

\author{
Eric L. Bruger (D) Daniel J. Snyder (D) Vaughn S. Cooper $\cdot$ Christopher M. Waters (iD)
}

Published online: 6 April 2021

(c) The Author(s), under exclusive licence to International Society for Microbial Ecology 2021

Correction to: The ISME Journal

https://doi.org/10.1038/s41396-020-00847-0
Unfortunately the spelling of the Daniel J. Snyder was incorrect.

The original article has been corrected. 